\title{
FORMULASI DAN KARAKTERISASI SEDIAAN HIDROGEL MINYAK CENGKEH (Syzygium aromaticum) BERBASIS KITOSAN
}

\author{
FORMULATION AND CHARACTERIZATION CHITOSAN BASED \\ HYDROGEL OF CLOVE OIL (Syzygium aromaticum)
}

\author{
Deasy Vanda Pertiwi*, Azis Ikhsanudin, Andina Kurnia Ningsih, Nining Sugihartini \\ Fakultas Farmasi, Universitas Ahmad Dahlan Yogyakarta \\ *Penulis Korespondensi, e-mail: deasy.pertiwi@pharm.uad.ac.id
}

\begin{abstract}
ABSTRAK
Eugenol merupakan kandungan utama minyak cengkeh yang memiliki potensi sebagai anti inflamasi. Bentuk sediaan yang berupa cairan berminyak menimbulkan ketidaknyamanan dan tidak bertahan lama untuk kontak dengan kulit sehingga efikasi yang diharapkan tidak tercapai jika digunakan langsung pada permukaan kulit. Oleh karena itu, dibutuhkan sistem sediaan yang dapat menghantarkan obat menembus kulit dengan lebih baik. Hidrogel adalah sediaan semipadat yang diharapkan dapat diaplikasikan sebagai pembawa minyak cengkeh, sehingga akan meningkatkan kenyamanan dan efikasinya. Pembuatan hidrogel minyak cengkeh dilakukan dengan memformulasikan minyak cengkeh, surfaktan tween 80 dan propilen glikol (PG) menjadi emulsi. Desain formula dibuat menggunakan Design Expert 10 trial. Formula emulsi yang optimum selanjutnya diformulasikan dengan basis gel kitosan konsentrasi $4 \%$ dan $5 \%$. Hidrogel minyak cengkeh diformulasikan menjadi emulsi yang selanjutnya ditambahkan ke dalam basis gel berupa kitosan. Dari hasil uji karakterisasi gel diperoleh bentuk emulgel berwarna putih kekuningan dengan $\mathrm{pH}$ 6. Uji daya sebar menunjukkan formula 1 dengan basis kitosan 5\% memiliki daya sebar yang paling baik, yaitu $5,1 \mathrm{~cm}$. Hasil uji daya lekat menunjukkan bahwa keempat formula memenuhi syarat uji daya lekat, yaitu tidak kurang dari 4 detik. Dari uji karakteristik, formula F1 5\% merupakan formula yang optimal karena memenuhi semua persyaratan sifat fisik. Hal tersebut menunjukkan bahwa minyak cengkeh dapat menghasilkan sediaan gel yang baik dengan basis kitosan.
\end{abstract}

Kata kunci : hidrogel, minyak cengkeh, kitosan, antiinflamasi

\section{ABSTRACT}

Eugenol is the main content of clove oil that has potential as an anti-inflammatory. The material that is oily liquids cause inconvenience and uncomfortable for contact with the skin, so the efficacy is not affective and not efficient. Therefore, it is need drugs delivery system that have better penetrate to the skin. Hidrogel is drugs delivery system that can be applied as a carrier of clove oil, so it will improve the comfort and efficacy. The making of hidrogel clove oil is start with formulated clove oil, tween 80 and PG into 
emulsion. Design formula design created using software Design Expert 10 trial. Optimum formula of emulsion was formulated with chitosan gel base concentration $4 \%$ and 5\%. The results from organoleptic observation of hidrogel was obtained gel forms a yellowish white emulgel with a $\mathrm{pH}$ 6. Result of scatterplot test shows formula 1 with base 5\% chitosan has the best power of spread, i.e. $5.1 \mathrm{~cm}$. Adhesion test show that the fourth formula comply the qualification of adhesion, that is not less than 4 seconds. It is shown that clove oil can yield a good hidrogel preparations with chitosan.

Keywords : hidrogel, clove oil, chitosan, aniinflammatory

\section{PENDAHULUAN}

Cengkeh merupakan tanaman rempah yang banyak tumbuh di daerah tropis, terutama Indonesia dan dikenal sebagai komoditas ekspor sejak awal abad ke-20. Minyak cengkeh memiliki kandungan utama berupa eugenol. Eugenol pada minyak cengkeh memiliki potensi menekan aksi NF-kB yang merupakan salah satu reseptor pada jalur inflamasi (Bachiega dkk., 2012). Eugenol menunjukkan efek antiinflamasi yang sama dengan antagonis COX (indometasin) dan antagonis COX-2 selektif (celecoxib) (Daniel dkk., 2009).

Minyak cengkeh yang digunakan secara topikal memiliki kelemahan yaitu penggunaan langsung dalam bentuk minyak dirasa kurang efektif dan kurang nyaman bagi pasien. Viskositas sediaan yang rendah mengakibatkan sulitnya sediaan yang berupa cairan minyak untuk menempel ketika diaplikasikan ke kulit. Oleh karena itu, perlu dikembangkan bentuk sediaan topikal yang lebih farmasetis dan lebih praktis (Pratimasari dkk., 2016).

Hidrogel merupakan sediaan semipadat yang terbentuk oleh jaringan hidrofilik yang memiliki kemampuan mengembang (swelling) dengan menyerap air atau cairan biologis namun tidak larut karena adanya ikatan silang (Peppas et al., 2000). Polimer larut air yang digunakan dalam formulasi hidrogel ini adalah kitosan. Kitosan bersifat biodegradable, biokompatibel, dan merupakan polyelektrolit alami karena memiliki gugus $\mathrm{NH}_{3}{ }^{+}$yang tinggi. Pembentukan hidrogel dengan basis kitosan memanfaatkan fenomena crosslinking polimer tersebut (Sun et al., 2007). 
Penelitian ini bertujuan untuk memformulasikan minyak cengkeh dalam bentuk hidrogel. Formulasi minyak cengkeh dalam sediaan hidrogel akan meningkatkan viskositasnya sehingga tepat diaplikasikan di permukaan kulit (Zhu et al., 2009). Minyak cengkeh, tween 80 sebagai surfaktan dan propilen glikol sebagai ko-surfaktan dibuat dalam bentuk emulsi agar dapat diformulasikan ke dalam basis polimer larut air. Setelah diperoleh formula emulsi yang optimal, ditambahkan biopolimer untuk membentuk hidrogel yaitu kitosan. Dengan komposisi formula hidrogel tersebut diharapkan menghasilkan sediaan hidrogel minyak cengkeh yang stabil dan diperoleh sistem penghantaran transdermal yang baik.

\section{METODE PENELITIAN}

Alat dan Bahan

Alat- alat yang digunakan adalah magnetic stirrer, $\mathrm{pH}$ meter, alat uji daya lekat, alat uji daya sebardan sentrifuge. Bahan-bahan yang digunakan adalah minyak cengkeh, tween 80 (Bratachem), propilen glikol (Bratachem), akuades, kitosan, natrium hidroksida (Bratachem), asam asetat glasial (Bratachem).

Jalannya Penelitian

Rancangan formula emulsi diperoleh menggunakan program Design Expert versi 10 trial. Komponen emulsi terdiri dari minyak cengkeh, tween 80 dan propilen glikol sebagai campuran surfaktan (s-mix) dan akuades sebagai fase air. Batas bawah dan batas atas dari tiga komponen variabel bebas, yaitu fase minyak, s-mix dan fase air diperoleh berdasarkan penelitian pendahuluan (Tabel I).

Tabel I. Batas komponen emulsi minyak cengkeh

\begin{tabular}{ccc}
\hline Komponen & Batas Bawah & Batas atas \\
\hline Minyak cengkeh & $10 \%$ & $15 \%$ \\
S-mix & $25 \%$ & $35 \%$ \\
Air & $55 \%$ & $65 \%$ \\
\hline
\end{tabular}

Optimasi Formula Emulsi Minyak Cengkeh

Emulsi dibuat dengan kandungan minyak cengkeh, tween 80, propilen glikol dan akuades sesuai dengan komposisi percobaan yang telah ditentukan melalui program Design Expert versi 10 trial (Tabel II). Campuran tween 80 dan propilen glikol (S-mix) digunakan perbandingan 2:1 karena memberikan area emulsi yang besar (Chen et al., 2006). Tween 80 dan propilen glikol dicampur dan diaduk selama 5 menit. Minyak 
kemudian dituang ke dalam campuran S-mix, lalu diaduk selama 15 menit. Campuran surfaktan, ko-surfaktan, dan minyak tersebut disonikasi selama 15 menit, kemudian diaduk kembali dengan memasukkan akuades tetes demi tetes. Campuran tersebut diaduk selama 10 menit, kemudian campuran tersebut disonikasi selama 10 menit. Semua proses pengadukan dilakukan dengan bantuan magnetic strirer.

Karakterisasi Formula Optimum Emulsi Minyak Cengkeh

Uji Stabilitas sentrifugasi

Setiap run (Tabel II) disentrifugasi dengan kecepatan 3500 rpm selama 30 menit dan diamati perubahan fisik yang terjadi. Stabilitas emulsi berdasarkan sentrifugasi dalam penelitian ini ditentukan secara katerogikal. Emulsi dikatakan tidak stabil apabila mengalami pemisahan fase dan diberikan nilai 1, sedangkan emulsi yang stabil diberikan nilai 0 .

Tabel II. Nilai respon stabilitas pengujian emulsi minyak cengkeh

\begin{tabular}{cccccc}
\hline Run & $\begin{array}{c}\text { Minyak } \\
(\%)\end{array}$ & S-mix (\%) & Air (\%) & $\begin{array}{c}\text { Stabilitas } \\
\text { sentrifugasi }(*)\end{array}$ & $\begin{array}{c}\text { Stabilitas Freeze } \\
\text { thaw cycles }(* *)\end{array}$ \\
\hline 1 & 12,5 & 30,625 & 56,875 & 0 & 3 \\
2 & 15,0 & 30,0 & 55,0 & 1 & 1 \\
3 & 10,0 & 25,0 & 65,0 & 1 & 1 \\
4 & 10,0 & 25,0 & 65,0 & 1 & 1 \\
5 & 12,5 & 32,5 & 55,0 & 1 & 1 \\
6 & 10,0 & 30 & 60,0 & 1 & 1 \\
7 & 12,5 & 25,0 & 62,5 & 1 & 1 \\
8 & 11,250 & 26,875 & 61,875 & 1 & 1 \\
9 & 13,750 & 28,125 & 58,125 & 1 & 1 \\
10 & 13,750 & 26,875 & 59,375 & 1 & 1 \\
11 & 15,0 & 30,0 & 55,0 & 1 & 3 \\
12 & 15,0 & 25,0 & 60,0 & 1 & 3 \\
13 & 10,0 & 35,0 & 55,0 & 0 & \\
14 & 10,0 & 35,0 & 55,0 & 0 & 1 \\
\hline
\end{tabular}

Ket : * : angka 1 menunjukkan emulsi mengalami pemisahan, angka 0 menunjukkan emulsi stabil. ** : angka 3 menunjukkan emulsi stabil selama 3 siklus, angka 1 menunjukkan emulsi stabil selama 1 siklus.

\section{Freeze thaw cycles}

Pengujian stabilitas freeze-thaw dilakukan dengan menggunakan metode perubahan suhu penyimpanan. Sampel disimpan pada suhu $-21^{\circ} \mathrm{C}$ selama 24 jam, kemudian dilanjutkan pada suhu $25^{\circ} \mathrm{C}$ selama 24 jam. Stabilitas emulsi dengan metode perubahan suhu penyimpanan dalam penelitian ini ditentukan secara katerogikal. Pengujian dilakukan hingga 3 siklus dengan pengamatan dilakukan pada akhir tiap 
siklus. Emulsi dikatakan stabil apabila sampai siklus ketiga emulsi tidak mengalami perubahan fisik.

Penentuan formula optimum emulsi minyak cengkeh

Formula optimum emulsi minyak cengkeh ditentukan berdasarkan hasil optimasi menggunakan program Design Expert versi 10 trial dengan variabel bebas komposisi minyak cengkeh, komposisi campuran surfaktan tween 80 dengan ko-surfaktan propilen glikol, dan komposisi air, dan variabel tergantung (respon yang diamati) yaitu stabilitas terhadap sentrifugasi, dan stabilitas freeze-thaw (Tabel II).

Pembuatan hidrogel minyak cengkeh

Fase minyak dibuat dengan mencampurkan minyak cengkeh, tween 80 dan propilen glikol seperti pembuatan formula emulsi. Kitosan sebagai gelling agent dilarutkan ke dalam $1 \%$ asam asetat. Gel didiamkan selama 24 jam, agar gel mengembang dengan baik. Setelah itu, fase minyak dimasukan ke dalam gel secara perlahan-lahan. Campuran tersebut diaduk dengan bantuan stirrer hingga homogen.

Karakterisasi Hidrogel Minyak cengkeh

Pemeriksaan organoleptis

Pemeriksaan dilakukan secara visual dengan melihat hidrogel yang dibuat berdasarkan warna, bau, dan bentuknya.

Pemeriksaan $\mathrm{pH}$

Pemeriksaan $\mathrm{pH}$ dilakukan dengan menggunakan kertas $\mathrm{pH}$ universal. Kertas $\mathrm{pH}$ dimasukan ke dalam hidrogel, kemudian dibandingkan dengan indikator $\mathrm{pH}$.

Uji daya sebar

Sejumlah 0,5 gram hidrogel diletakan di bagian tengah alat uji daya sebar. Kaca penutup bagian atas ditimbang, kemudian diletakkan pada alat tersebut. Kaca penutup dibiarkan selama 1 menit, kemudian diukur diameter hidrogel dengan 4 sisi pengukuran. Beban seberat 50, 100, 150, 200, dan 250 gram selanjutnya diberikan ke dalam alat uji 
daya sebar dengan interval 1 menit. Diameter hidrogel diukur dengan 4 sisi pengukuran pada setiap pemberian beban dan waktu yang telah ditentukan.

Uji daya lekat

Sejumlah 0,1 gram nanoemulgel ditimbang, kemudian diletakkan ke dalam kaca preparat yang sudah diberi tanda $2 \mathrm{~cm}$. Setelah itu, kaca preparat lain diletakkan di atasnya, kemudian diberi beban $1 \mathrm{Kg}$ selama 5 menit dan diletakan dalam alat uji daya lekat. Pengukuran daya lekat dilakukan dengan mengukur waktu dari awal alat uji dijalankan hingga kaca preparat tersebut terpisah.

\section{HASIL DAN PEMBAHASAN}

Hidrogel yang merupakan sediaan semipadat berbasis air sesuai sebagai pembawa minyak cengkeh. Minyak cengkeh yang memiliki sifat dapat menimbulkan iritasi karena sedikit panas diharapkan dapat diperbaiki sifatnya dengan gel berbasis air. Minyak cengkeh dibuat dalam bentuk emulsi sebelum diformulasikan ke dalam basis gel agar dapat bercampur homogen dengan basis gel dan membentuk sediaan hidrogel yang stabil. Emulsi minyak cengkeh menggunakan campuran surfaktan - kosurfaktan (s-mix) tween 80 dan propilen glikol.

\section{Optimasi Formula Emulsi Minyak Cengkeh}

Desain optimasi formula emulsi minyak cengkeh ditentukan menggunakan Design expert versi 10 trial. Dari rancangan formula, diperoleh 14 run formula dengan 2 respon yaitu stabilitas sentrifugasi dan stabilitas freeze thaw (Tabel II). Hasil pengujian stabilitas sentrifugasi dianalisis dengan Design Expert 10 trial untuk melihat pengaruh masing-masing komponen penyusun emulsi terhadap stabilitas. Berdasarkan persamaan simplex lattice design yang diperoleh (Persamaan 1), campuran surfaktan memberikan pengaruh positif terhadap stabilitas emulsi secara gaya sentrifugasi. Semakin banyak s-mix yang digunakan akan meningkatkan stabilitas dari emulsi yang dihasilkan (Gambar 1).

Hidrogel yang merupakan sediaan semipadat berbasis air sesuai sebagai pembawa minyak cengkeh. Minyak cengkeh yang memiliki sifat dapat menimbulkan iritasi karena 
sedikit panas diharapkan dapat diperbaiki sifatnya dengan gel berbasis air. Minyak cengkeh dibuat dalam bentuk emulsi sebelum diformulasikan ke dalam basis gel agar dapat bercampur homogen dengan basis gel dan membentuk sediaan hidrogel yang stabil. Emulsi minyak cengkeh menggunakan campuran surfaktan - kosurfaktan (s-mix) tween 80 dan propilen glikol.

\section{Optimasi Formula Emulsi Minyak Cengkeh}

Desain optimasi formula emulsi minyak cengkeh ditentukan menggunakan Design expert versi 10 trial. Dari rancangan formula, diperoleh 14 run formula dengan 2 respon yaitu stabilitas sentrifugasi dan stabilitas freeze thaw (Tabel II). Hasil pengujian stabilitas sentrifugasi dianalisis dengan Design Expert 10 trial untuk melihat pengaruh masing-masing komponen penyusun emulsi terhadap stabilitas. Berdasarkan persamaan simplex lattice design yang diperoleh (Persamaan 1), campuran surfaktan memberikan pengaruh positif terhadap stabilitas emulsi secara gaya sentrifugasi. Semakin banyak s-mix yang digunakan akan meningkatkan stabilitas dari emulsi yang dihasilkan (Gambar 1).

$$
\begin{gathered}
\mathrm{Y}=-626,837(\text { minyak })+52,035(\mathrm{~S}-\mathrm{mix})-10,170(\text { air })+10,553(\text { minyak })(\mathrm{s}- \\
\operatorname{mix})+10,905(\text { minyak })(\text { air })-0,77959(\mathrm{~s}-\mathrm{mix})(\mathrm{air}) \\
\mathrm{Y}=\text { Stabilitas sentrifugasi }
\end{gathered}
$$

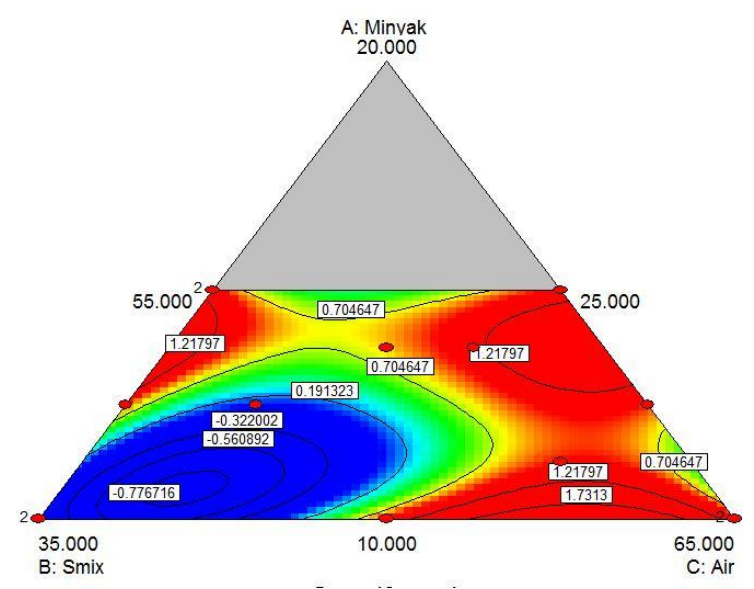

Gambar 1. Contour plot Respon uji stabilitas terhadap sentrifugasi

Analisis ANOVA hasil pengujian stabilitas freeze thaw menghasilkan persamaan simplex lattice design Persamaan 2, campuran surfaktan memberikan 
pengaruh positif terhadap stabilitas emulsi secara gaya freeze thaw. Minyak memperikan pengaruh positif yang sangat besar terhadap stabilitas emulsi. Semakin banyak s-mix yang digunakan, semakin meningkatkan stabilitas emulsi (Gambar 2).

$$
\begin{gathered}
\mathrm{Y}=1253,704 \text { (minyak)-104,040(S-mix)+20,370 (air)-21,107 (minyak)(s-mix)- } \\
21,810(\text { minyak)(air)+1,559 (s-mix)(air) } \\
\mathrm{Y}=\text { Stabilitas freeze thaw (siklus) }
\end{gathered}
$$

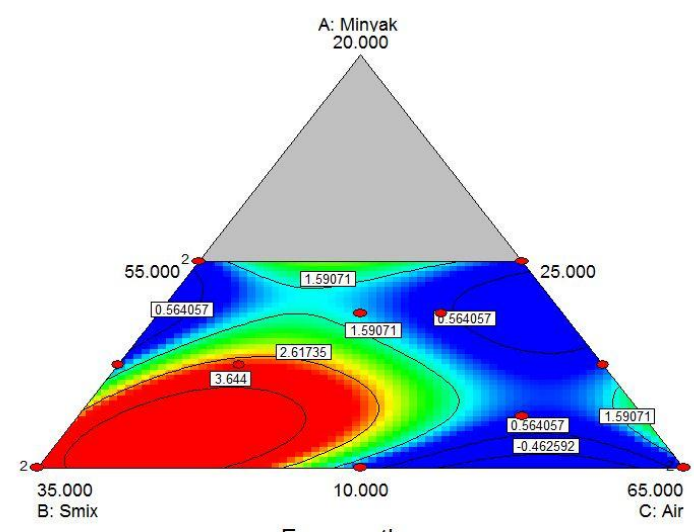

Gambar 2. Contour plot Respon uji stabilitas freeze thaw

Hasil analisis ANOVA menunjukkan nilai p-value kurang dari 0,05 $(0,0082)$ dan menunjukkan model yang signifikan sehingga cukup menjelaskan bahwa model tersebut dapat dipergunakan.

Berdasarkan analisa data uji stabilitas sentrifugasi dan uji stabillitas freeze thaw, diperoleh 3 formula terpilih sebagai kandidat formula optimum (Tabel III). Ketiga kandidat formula optimum diformulasikan dan dilakukan verifikasi karakteristiknya untuk selanjutnya diformulasikan ke dalam basis gel kitosan. 
Tabel III. Formula optimum dari hasil Simplex Lattice Design

\begin{tabular}{ccccccc}
\hline Formula & $\begin{array}{c}\text { Minyak } \\
(\%)\end{array}$ & $\begin{array}{c}\text { S-mix } \\
(\boldsymbol{\%})\end{array}$ & $\begin{array}{c}\text { Air } \\
(\boldsymbol{\%})\end{array}$ & $\begin{array}{c}\text { Stabilitas } \\
\text { sentrifugasi }\end{array}$ & $\begin{array}{c}\text { Stabilitas } \\
\text { Freeze } \\
\text { thaw } \\
\text { cycles }\end{array}$ & Desirability \\
\hline F1 & 15,0 & 28,06 & 56,94 & 0 & 3 & 0,808 \\
F2 & 12,42 & 30,47 & 57,11 & 0 & 3 & 0,757 \\
F3 & 11,40 & 25,0 & 63,59 & 1 & 1 & 0,408 \\
\hline
\end{tabular}

Verifikasi karakteristik emulsi minyak cengkeh yang dibuat menunjukkan bahwa formula dengan hasil stabilitas baik terdapat pada formula 1 dan 2. Pada kedua formula tersebut, emulsi tidak mengalami pemisahan baik pada uji stabilitas dengan sentrifugasi maupun dengan metode freeze thaw. Selanjutnya kedua formula emulsi (F1 dan F2) diformulasikan ke dalam basis hidrogel kitosan konsentrasi $4 \%$ dan $5 \%$.

Uji karakteristik hidrogel minyak cengkeh

Pada penelitian ini, digunakan basis gel kitosan dengan konsentrasi $4 \%$ dan $5 \%$. Kitosan pada kedua konsentrasi tersebut dan pH 6 membentuk basis gel yang baik. Gel minyak cengkeh yang dihasilkan selanjutnya diuji sifat fisiknya.

Pemeriksaan organoleptis terhadap 4 formula gel minyak cengkeh yang dibuat menghasilkan gel dengan karakteristik sebagai berikut :

Tabel IV. Pemeriksaan Organoleptis dan $\mathrm{pH}$

\begin{tabular}{lllll}
\hline Pengamatan & FI 4\% & F2 4\% & F1 5\% & F2 5\% \\
\hline Bentuk & Emulgel & Emulgel & Emulgel & Emulgel \\
Konsistensi & Kental & Kental & Sangat & Sangat \\
& & & Kental & Kental \\
Warna & Putih & Putih & Putih & Putih \\
\multirow{2}{*}{ pH } & Kekuningan & Kekuningan & Kekuningan & Kekuningan \\
\hline
\end{tabular}

F1 4\% : formula emulsi F1 dalam kitosan 4\%; F2 4\% : formula emulsi F2 dalam kitosan 4\%; F1 $5 \%$ : formula emulsi F1 dalam kitosan 4\%; F2 5\% : formula emulsi FI dalam kitosan 5\% 
Dari pemeriksaan organoleptis menunjukkan bahwa emulgel yang diperoleh sudah sesuai dan $\mathrm{pH}$ sediaan yaitu pada rentang $\mathrm{pH}$ kulit 4,5-7 (Naibaho et al., 2013). Nilai $\mathrm{pH}$ yang mendekati $\mathrm{pH}$ kulit diharapkan tidak menimbulkan iritasi maupun efek samping lain ketika hidrogel diaplikasikan langung ke kulit.

Uji daya sebar pada gel dilakukan untuk melihat kemampuan sediaan menyebar pada kulit, sehingga menjamin pemberian obat yang memuaskan (Naibaho et al., 2013). Daya sebar yang baik untuk sediaan topikal adalah 5-7 cm (Ulaen et al., 2012).

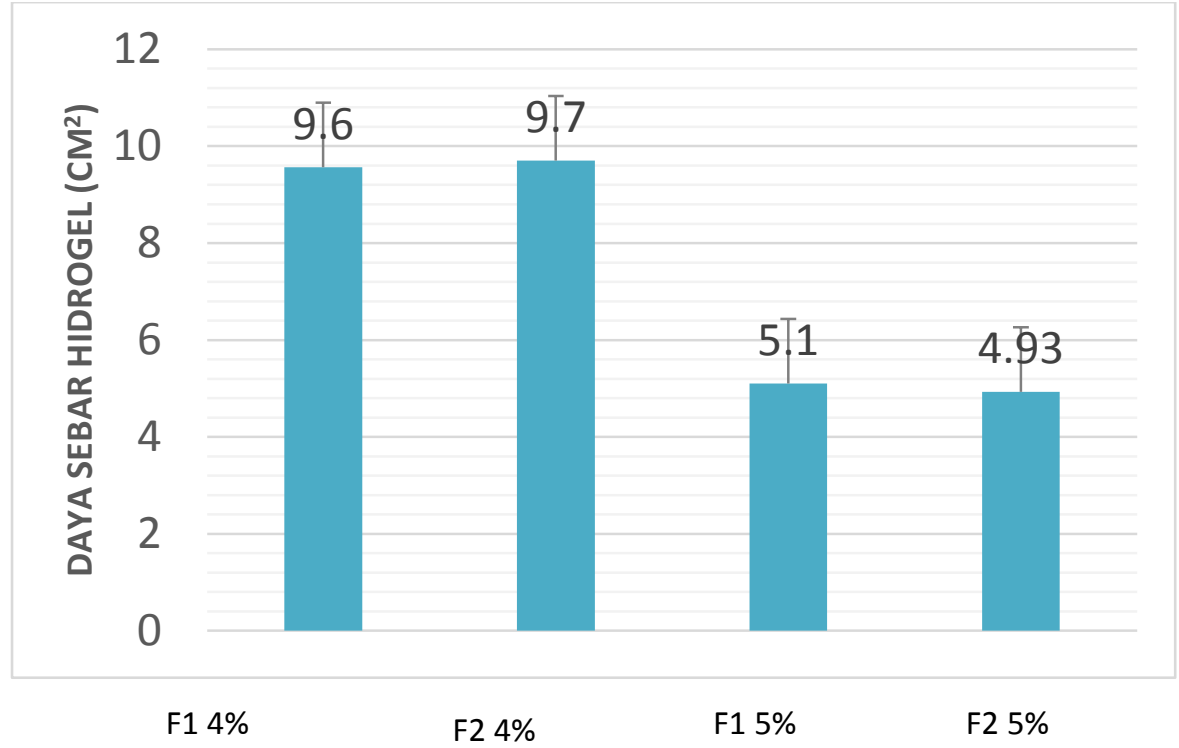

Gambar 3. Grafik daya sebar hidrogel minyak cengkeh

Berdasarkan data yang diperoleh, formula yang memenuhi syarat daya sebar untuk sediaan topikal 5-7 $\mathrm{cm}^{2}$ dengan beban 100 gr per menit adalah formula F1 dalam basis gel kitosan konsentrasi $5 \%$ dengan daya sebar $5,1 \mathrm{~cm}^{2}$ dengan beban 100 gr pada pengamatan 1 menit.

Uji daya lekat bertujuan untuk mngetahui kemampuan hidrogel untuk kontak dengan kulit. Syarat daya lekat sediaan topikal adalah tidak kurang dari 4 detik (Ulaen et al., 2012). Berdasarkan hasil yang diperoleh dari uji daya lekat, keempat formula yang dibuat menunjukkan daya lekat yang memenuhi syarat yaitu > 4 detik. Daya lekat paling tinggi ditunjukkan oleh formula F2 dengan basis gel kitosan konsentrasi 5\%. Hal tersebut menunjukkan semakin tinggi konsentrasi kitosan, maka semakin besar daya sebar yang diberikan. Hasil dari pengujian daya lekat menunjukkan hidrogel minyak 
cengkeh yang diformulasikan memberikan waktu daya lekat sekitar 60 detik. Waktu daya lekat yang cukup lama diharapkan memberikan efikasi yang baik.

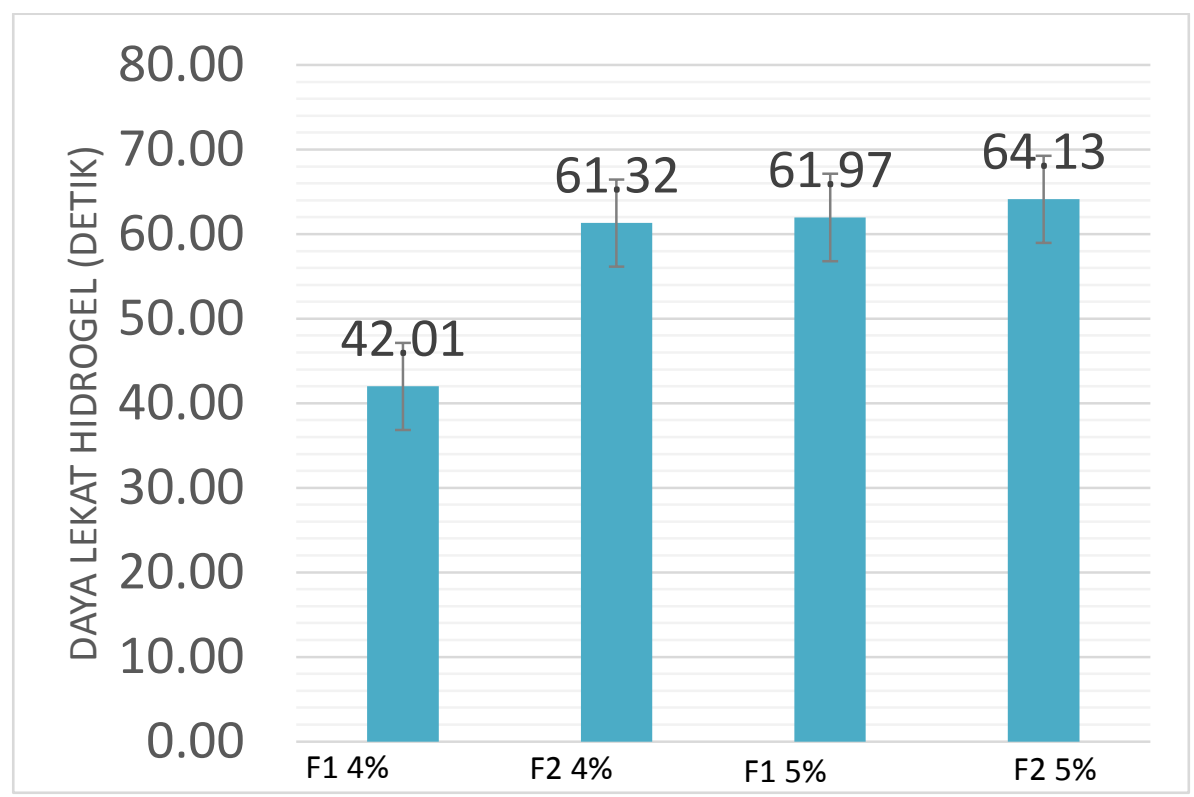

Gambar 4. Grafik daya lekat hidrogel minyak cengkeh

\section{KESIMPULAN}

Formulasi hidrogel minyak cengkeh dapat dilakukan dengan mengemulsikan minyak cengkeh dengan surfaktan tween 80 dan propilen glikol, Formula emulsi terpilih adalah formula dengan perbandingan komposisi minyak, s-mix, dan air yaitu 15,0; 28,$061 ; 56,939$ dan 12,$424 ; 30,469 ; 57,107$ yang selanjutnya didispersikan ke dalam basis gel kitosan $4 \%$ dan 5\%. Dari uji karakteristik yang dilakukan, formula hidrogel yang paling baik diperoleh dari F1 dengan basis kitosan 5\%, karena memberikan nilai daya sebar dan daya lekat memenuhi persyaratan.

\section{DAFTAR PUSTAKA}

Bachiega, T.F., de Sousa, J.P.B., Bastos, J.K., dan Sforcin, J.M., 2012, Clove and Eugenol in Noncytotoxic Concentrations Exert Immunomodulatory/antiinflammatory Action on Cytokine Production by Murine Macrophages, Journal of Pharmacy and Pharmacology, 64: 610-616. 
Chen, H., Khemtong, C., Yang, X., Chang, X., dan Gao, J., 2011, Nanonization Strategies for Poorly Water-Soluble Drugs, Drug discovery today, 16: 354-360.

Daniel, A.N., Sartoretto, S.M., Schmidt, G., Caparroz-Assef, S.M., Bersani-Amado, C.A., dan Cuman, R.K.N., 2009, Anti-inflammatory and Antinociceptive Activities A of Eugenol Essential Oil in Experimental Animal Models. Revista Brasileira de Farmacognosia, 19: 212-217.

Naibaho, D.H., Yamkan, V,Y., Weni, W., 2013, Pengaruh Basis Salep Terhadap Formulasi Sediaan Salep Ekstrak Daun Kemangi (Ocinum sanchum L.) pada Kulit Punggung Kelinci yang dibuat Infeksi Staphylococcus aureus, Jurnal ilmiah Farmasi - UNSRAT, (2) 2.

Peppas, N.A., Bures, P., Leobandung, W., dan Ichikawa, H., 2000, Hydrogels in pharmaceutical formulations, European Journal of Pharmaceutics and Biopharmaceutics, 50: 27-46.

Pratimasari, D., Sugihartini, N., dan Yuwono, T., 2016, Evaluasi Sifat Fisik dan Uji Iritasi Sediaan Salep Minyak Atsiri Bunga Cengkeh dalam Basis Larut Air, Jurnal Ilmiah Farmasi, 11: 9-15.

Sun, G., Zhang, X.-Z., dan Chu, C.-C., 2007, Formulation and characterization of chitosan-based hydrogel films having both temperature and $\mathrm{pH}$ sensitivity, Journal of Materials Science: Materials in Medicine, 18: 1563-1577.

Ulaen, Selfie P.J., Banne, Yos Suatan \& Ririn A., 2012, Pembuatan Salep Anti Jerawat dari Ekstrak Rimpang Temulawak (Curcuma xanthorrhiza Roxb.), Jurnal Ilmiah Farmasi, 3(2), 45-49.

Zhu, W., Guo, C., Yu, A., Gao, Y., Cao, F., dan Zhai, G., 2009, Microemulsion-Based Hydrogel Formulation of Penciclovir for Topical Delivery, International Journal of Pharmaceutics, 378: 152-158. 